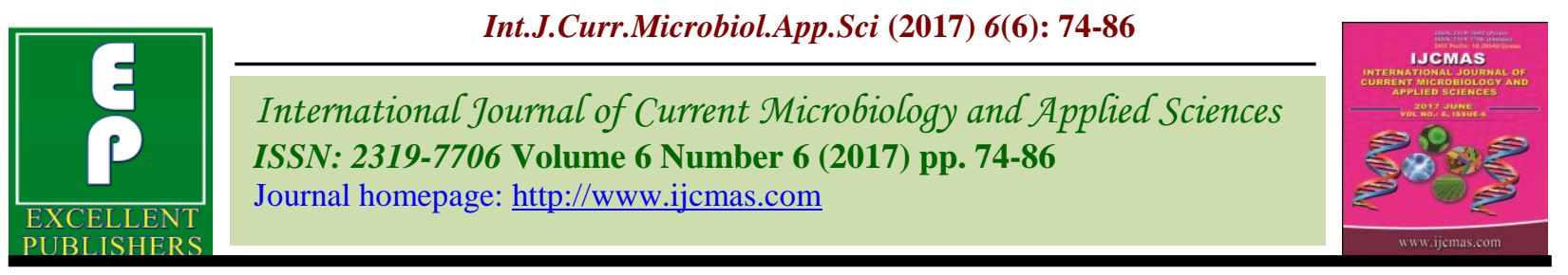

Original Research Article

https://doi.org/10.20546/ijcmas.2017.606.008

\title{
Evaluation of Bioactive Nano Composite Fillers Effect on Wear Resistance of Composite and Enamel Surfaces
}

\author{
Ola M. Sakr ${ }^{1,2} *$ \\ ${ }^{1}$ Department of Conservative Dentistry, College of Dentistry, Qassim University, \\ Kingdom of Saudi Arabia \\ ${ }^{2}$ Department of Operative Dentistry, College of Dentistry, Misr University for \\ Science and Technology, Egypt \\ *Corresponding author
}

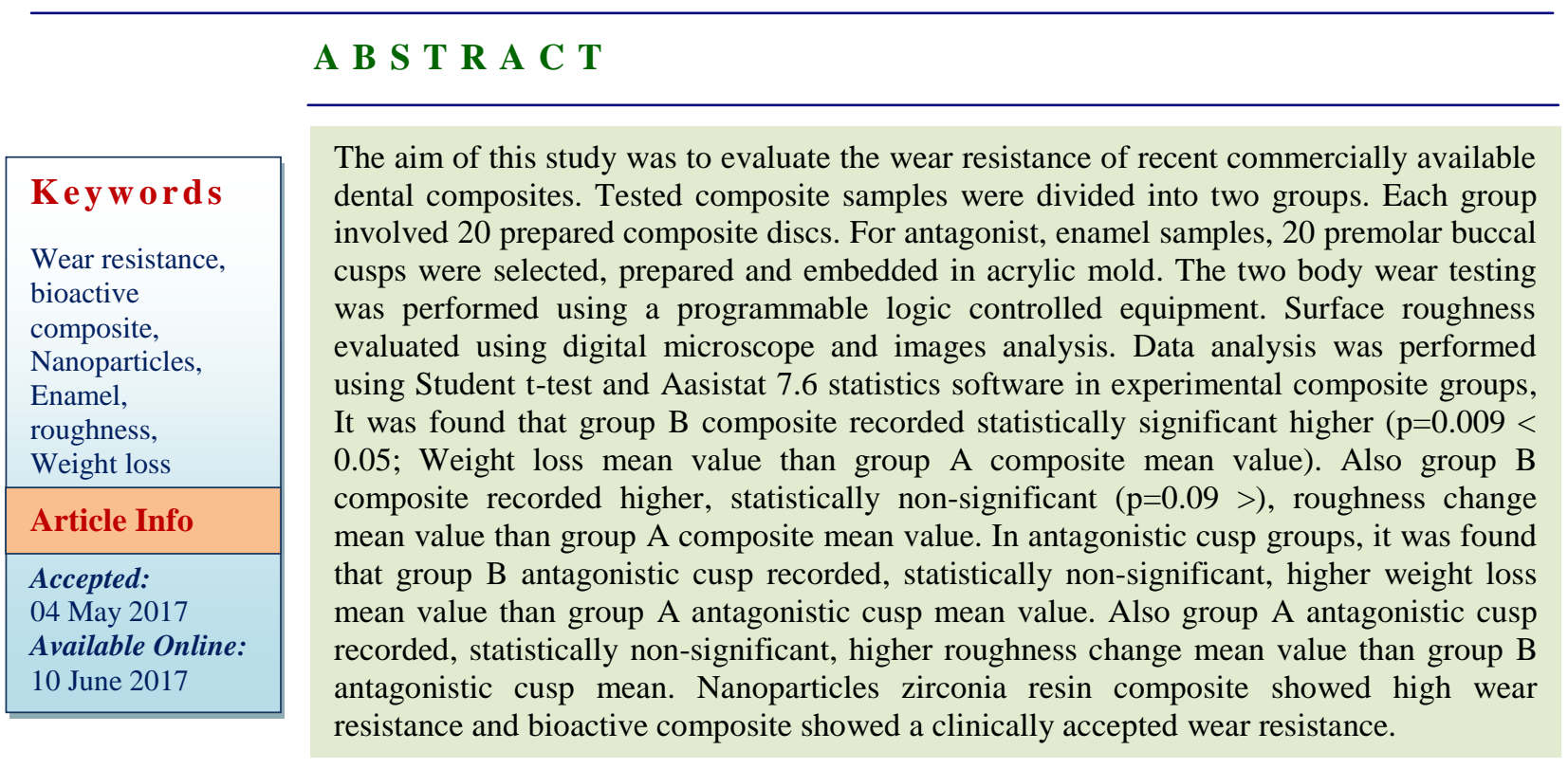

\section{Introduction}

Recently dental resin composites are considered as perfect option for treatment all types of restorations Kurachi et al., (2001), Pontons-Melo et al., (2012) and Bartlett et al., (2006).

Application of direct and indirect resin composites takes place to build up the occlusion in cases of extensive tooth wear Attin et al., (2012), Pontons-Melo et al., (2011), Vailati et al., (2012) and Ferracane (2013).
The reason of teeth wear (bruxism, erosion or combination of both), will effect on success or failure of resin composite dental restorations. As failure of direct resin composite represented by wear, fracture and recurrent caries Vailati et al., (2012) and Ferracane (2013), Wilder (1999) and Da Rosa Rodolpho et al., (2006).

Nowadays, polymer matrix was dispersed by nanoparticles in hybrid system of dental resin 
composites, this system was received extensive attention from dentists (Lai et al., 2007; Mitr, 2003).

Wear resistance is one of the most important of mechanical properties of restorative materials, which determines the success or failure and shelf life of resin composites (Suwannaroop et al., 2011).

Normally in oral cavity, Restorative material wear results from direct contact between the tooth and the restorations during mastication, parafunctional stresses, and abrasive particles tooth brushing and dietary factors which introduce chemical factors to oral media (Braga et al., 2010; Hahnel et al., 2009).

Wear of dental restorations will be a main reason in structure alteration which may result in loss of vertical dimension of occlusion with subsequent teeth occlusion alteration and faulty tooth relationship with esthetic loss.

Lack of sufficient wear resistance will result in excessive reduction in structure, resulting in loss of posterior tooth support, loss of masticatory efficiency, alterations in the functional path of masticatory movement, fatigue of masticatory muscles (Suwannaroop et al., 2011; Ghazal et al., 2008; Hirata, 2011).

Nanoparticles used in biomedical dental restorative materials to improve mechanical properties and increase wear resistance of used material (Xia et al., 2008; Tian et al., 2008).

The load transfer from polymer matrix to nanoparticles is enhanced through large specific nanoparticles (size $<100 \mathrm{~nm}$ ) surface area than microparticales (size>100 nm) (Mitra, 2003). Therefore, in this study we hypothesize that these nanoparticles might improve wear resistance of tested nano bioactive composites. The objective of this study was to investigate the effect of nano bioactive particles on wear resistance of tested materials against natural teeth.

\section{Materials and Methods}

Two direct commercially available dental nanocomposites were tested in this study, their manufacturers, composition and lot number are summarized in table 1.

Composite samples were divided into two group as follow:

Group A representing 20 discs of Filtek Z350 $\mathrm{XT}$ and

Group B representing 20 discs of Bio active restorative.

\section{Samples preparation}

Twenty disc shaped (10 mm diameter x $2 \mathrm{~mm}$ thick) samples of each tested nanocompsite materials group were prepared according to the manufacturer's instructions.

Each type of tested resin composite was inserted in a cylindrical Teflon mold $(10 \mathrm{~mm}$ diameter $\mathrm{x} 2 \mathrm{~mm}$ thick) and backed with polyester strip (Mylar, Moyco Union Broach, York, PA, USA). The top surface of the mold was then covered with another polyester strip.

Filtek Z350 XT and Bio active restorative were cured for $40 \mathrm{~s}$ using a conventional halogen light curing unit, which had a light intensity of $450-470 \mathrm{~mW} / \mathrm{cm} 2$ (Monitex, Blue LEX, LD-105, Taiwan) (Fig. 1).

For Antagonist Samples, Twenty upper Premolar halves (Sound non carious buccal Cusps) were selected and prepared. Premolars buccal cusps were embedded in circular acrylic block with $20 \mathrm{~mm}$ diameter $25, \mathrm{~mm}$ height and fixed to wear test machine used as illustrated in figure 2 . 


\section{Two-body wear test}

The two body wear testing was performed using a programmable logic controlled equipment; the newly developed four stations multimodal ROBOTA chewing simulator integrated with thermo-cyclic protocol operated on servo-motor (Model ACH09075DC-T, AD-Tech Technology Co., Ltd., Germany).

ROBOTA chewing simulator which has four chambers simulating the vertical and horizontal movements simultaneously in the thermodynamic condition. Each of the chambers consists of an upper Jackob's chuckas tooth antagonist holder that can be tightened with a screw and a lower plastic sample holder in which the specimen can be embedded. The composite specimens were embedded in Teflon housing in the lower sample holder (Fig. 3). A weight of $5 \mathrm{~kg}$, which is comparable to $49 \mathrm{~N}$ of chewing force was exerted. The test was repeated 10, 000 times to clinically simulate the 1 month chewing condition, accompanying thermocycling according to previous studies (Table 2) (Yu-Seok, 2010).

The substance loss of the specimens after loading was measured by weighting in the electronic analytical balance (Sartorius, Biopharmaceutical and Laboratories, Germany) with an accuracy of 0.0001 gr. to weight the difference in weight before and after 37, 500 cycles. As this electronic balance had a fully automated calibration technology and a micro weighting scale, values of all the mounted discs and antagonist samples were accurately measured. Each mounted sample was cleaned and dried with tissue paper before weighing. To ensure accuracy, the balance was kept on a free standing table at all times - away from vibrations - and weighed the specimens with the glass doors of the balance closed to avoid the effect of air drafts (Fig. 4).

\section{Roughness methodology}

The optical methods tend to fulfill the need for quantitative characterization of surface topography without contact (Ossama et al., 2010). Specimens were photographed using USB digital microscope with a built-in camera (Scope Capture Digital Microscope, Guangdong, China; Fig. 4) connected with an IBM compatible personal computer using a fixed magnification of $120 \mathrm{X}$. The images were recorded with a resolution of $1280 \times$ 1024 pixels per image. Digital microscope images were cropped to $350 \times 400$ pixels using Microsoft office picture manager to specify/standardize area of roughness measurement. The cropped images were analyzed using WSxM software (Ver5 develop 4.1, Nanotec, Electronica, SL) (Horcas et al., 2007). Within the WSxM software, all limits, sizes, frames and measured parameters are expressed in pixels. Therefore, system calibration was done to convert the pixels into absolute real world units. Calibration was made by comparing an object of known size (a ruler in this study) with a scale generated by the software. WSxM software was used to calculate average of heights ( $\mathrm{Ra}$ ) expressed in $\mu \mathrm{m}$, which can be assumed as a reliable indices of surface roughness (Kakaboura, 2007).

Subsequently, a 3D image of the surface profile of the specimens was created using A digital image analysis system (Image J 1.43U, National Institute of Health, USA) (Fig. 5).

\section{Statistical analysis}

Data analysis was performed in several steps. Initially, descriptive statistics for each group results. Student t-test was performed to detect significant difference between groups. Statistical analysis was performed using Aasistat 7.6 statistics software for Windows (Campina Grande, Paraiba state, Brazil). P values $\leq 0.05$ are considered to be statistically significant in all tests. 


\section{Results and Discussion}

\section{Wear}

The mean values and standard deviations (SD) for wear measured by weight loss (gram) recorded on both materials before and after wear simulation cycles summarized in table 3 and graphically represented in figure 5. The wear recorded for the antagonistic cusps is also shown.

\section{Weight}

\section{In experimental composite groups}

It was found that group B composite recorded higher weight loss mean value $(0.00592 \pm 0.0018$ gr) than group A composite mean value $(0.00027 \pm 0.0004 \mathrm{gr})$.

The difference between both groups was statistically significant as indicated by t-test $(\mathrm{p}=0.009<0.05)($ Table 4$)$.

\section{In antagonistic cusp groups}

It was found that group B antagonistic cusp recorded higher weight loss mean value $(0.01 \pm 0.002 \mathrm{gr})$ than group A antagonistic cusp mean value $(0.0049 \pm 0.005 \mathrm{gr})$.

The difference between both groups was statistically non-significant as indicated by ttest $(\mathrm{p}=0.2947>0.05)$ (Table 4).

\section{Roughness}

The mean values and standard deviations (SD) for roughness measured by average roughness $\mathrm{Ra}(\mu \mathrm{m})$ recorded on both materials before and after wear simulation cycles and summarized in tables 5 and 6 . It is graphically represented in figures 6-12. The roughness recorded for the antagonistic cusps is also shown.

\section{In experimental composite groups}

It was found that group B composite recorded higher roughness change mean value $(0.00079 \pm 0.0007 \mathrm{Ra})$ than group A composite mean value $(-0.00067 \pm 0.0003 \mathrm{Ra})$. The difference between both groups was statistically non-significant as indicated by ttest $(\mathrm{p}=0.09>0.05)$.

\section{In antagonistic cusp groups}

It was found that group A antagonistic cusp recorded higher roughness change mean value $(0.00077 \pm 0.0006 \mathrm{Ra})$ than group $\mathrm{B}$ antagonistic cusp mean value ($0.00057 \pm 0.0004 \mathrm{Ra})$. The difference between both groups was statistically non-significant as indicated by $\mathrm{t}$-test $(\mathrm{p}=0.0537>0.05)$.

Development of bioactive dental composite restorations requires clinical and laboratory evaluation techniques to permit assessment of its mechanical clinical properties coincide with its biological properties. Bioactive dental composite surface wear is an important mechanical clinical property to be investigated.

DeLong et al., (2012) mentioned that dental composites wear measuring assume that occlusal forces and contact paths, which are highly variable both within and between subjects, can be represented by average values that remain relatively stable with time.

Recent dental restoration and Natural teeth wear resistance are an important property to be studied. Absence of wear resistance can be a major cause of vertical dimension loss with subsequent of temporo-madibular joint dysfunction. This was clear in patients with para-functional pathology e.g. bruxism and clenching. That can lead to myofacial muscle dysfunction, pain and headaches. Also reaching healthy oral cavity equilibrium will be difficult (Olivera, 2008). 
Table.1 Composition, lot number and manufacture of the tested materials

\begin{tabular}{|c|c|c|c|}
\hline Material & composition & Lot number & Manufacture \\
\hline Filtek Z350 XT & $\begin{array}{c}\text { (20 nm silica filler 4-11 nm zirconia } \\
\text { filler) as 72.5\% by willer bis- } \\
\text { GMA, UDMA, TEGDMA, } \\
\text { PEGDMA and bis-EMA resins }\end{array}$ & N339145 & 3M ESPE \\
\hline $\begin{array}{c}\text { Bio active } \\
\text { restorative }\end{array}$ & $\begin{array}{c}56 \% \text { by weight reactive glass } \\
\text { particles that mimic physical and } \\
\text { chemical properties of natural teeth., } \\
\text { shock absorbing ionic resin } \\
\text { component containing acidic } \\
\text { monomer with antimicrobial } \\
\text { properties.no Bisphenol A, No } \\
\text { BisGMA, no BPA derivatives' }\end{array}$ & 150318 & PULPDENT \\
& Corporation \\
& & & \\
\hline
\end{tabular}

Table.2 Wear test parameters

\begin{tabular}{|c|c|}
\hline Cold/hot bath temperature: $5^{\circ} / 55^{\circ} \mathrm{C}$ & Dwell time: $60 \mathrm{~s}$ \\
\hline Vertical movement: $1 \mathrm{~mm}$ & Horizontal movement: $2 \mathrm{~mm}$ \\
\hline Rising speed: $90 \mathrm{~mm} / \mathrm{s}$ & Forward speed: $90 \mathrm{~mm} / \mathrm{s}$ \\
\hline Descending speed: $40 \mathrm{~mm} / \mathrm{s}$ & Backward speed: $40 \mathrm{~mm} / \mathrm{s}$ \\
\hline Cycle frequency $1.6 \mathrm{~Hz}$ & Weight per sample: from $5 \mathrm{~kg}$ \\
\hline \multicolumn{2}{|c|}{ Torque; $2.4 \mathrm{~N} . \mathrm{m}$} \\
\hline
\end{tabular}

Table.3 Weight results (Mean values \pm SD) for both experimental groups and cusp antagonist before and after wear simulation

\begin{tabular}{|c|c|c|c|c|c|}
\hline \multicolumn{2}{|c|}{ Variables } & \multicolumn{2}{c|}{ Samples } & \multicolumn{2}{c|}{ Antagonistic cusp } \\
\cline { 3 - 6 } & Before & After & Before & After \\
\hline \multirow{2}{*}{$\begin{array}{c}\text { Composite } \\
\text { group }\end{array}$} & Group A & $0.1577 \pm 0.003$ & $0.1572 \pm 0.004$ & $0.5524 \pm 0.062$ & $0.5475 \pm 0.056$ \\
\cline { 2 - 6 } & Group B & $0.1590 \pm 0.001$ & $0.15308 \pm 0.006$ & $0.5119 \pm 0.0527$ & $0.5019 \pm 0.0516$ \\
\hline
\end{tabular}

Table.4 Weight loss results (Mean values \pm SD) for both experimental groups and antagonist as function of wear simulation

\begin{tabular}{|c|c|c|c|c|c|c|c|}
\hline \multirow{2}{*}{ Variables } & \multicolumn{3}{|c|}{ Samples } & \multicolumn{3}{c|}{ Antagonistic cusp } \\
\cline { 3 - 8 } \multicolumn{2}{|c|}{} & \multirow{2}{*}{ Mean \pm SEM } & \multicolumn{2}{|c|}{$95 \%$ CI } & Mean \pm SEM & \multicolumn{2}{c|}{$95 \%$ CI } \\
\cline { 3 - 8 } & Lower & Upper & & Lower & Upper \\
\hline $\begin{array}{c}\text { Composite } \\
\text { group }\end{array}$ & Group A & $0.00053 \pm 0.0002$ & 0.0001 & 0.001 & $0.0049 \pm 0.005$ & -0.0064 & 0.01624 \\
\cline { 2 - 8 } & Group B & $0.00592 \pm 0.0018$ & 0.0018 & 0.01 & $0.01 \pm 0.002$ & 0.0048 & 0.0153 \\
\hline ANOVA & P value & \multicolumn{2}{|c|}{$0.009 *$} & \multicolumn{3}{c}{$0.2947 \mathrm{~ns}$} \\
\hline
\end{tabular}

CI; Confidence intervals*; significant $(p<0.05) \mathrm{ns}$; non-significant $(\mathrm{p}>0.05)$ 
Table.5 Roughness results (Mean values \pm SD) for experimental groups and cusp antagonist before and after wear simulation

\begin{tabular}{|c|c|c|c|c|c|}
\hline \multicolumn{2}{|c|}{ Variables } & \multicolumn{2}{c|}{ Samples } & \multicolumn{2}{c|}{ Antagonistic cusp } \\
\cline { 3 - 6 } & Before & After & Before & After \\
\hline \multirow{2}{*}{$\begin{array}{c}\text { Composite } \\
\text { group }\end{array}$} & Group A & $0.2557 \pm 0.0009$ & $0.2550 \pm 0.0007$ & $0.2555 \pm 0.0013$ & $0.2563 \pm 0.001$ \\
\cline { 2 - 6 } & Group B & $0.2555 \pm 0.0008$ & $0.2562 \pm 0.0015$ & $0.2567 \pm 0.0008$ & $0.2561 \pm 0.0007$ \\
\hline
\end{tabular}

Table.6 Roughness change results (Mean values \pm SD) for both experimental groups and antagonist as function of wear simulation

\begin{tabular}{|c|c|c|c|c|c|c|c|}
\hline \multirow{3}{*}{\multicolumn{2}{|c|}{ Variables }} & \multicolumn{3}{|c|}{ Samples } & \multicolumn{3}{|c|}{ Antagonistic cusp } \\
\hline & & \multirow{2}{*}{ Mean \pm SEM } & \multicolumn{2}{|c|}{$95 \% \mathrm{CI}$} & \multirow{2}{*}{ Mean \pm SEM } & \multicolumn{2}{|c|}{$95 \% \mathrm{CI}$} \\
\hline & & & Lower & Upper & & Lower & Upper \\
\hline \multirow{2}{*}{$\begin{array}{c}\text { Composite } \\
\text { group }\end{array}$} & Group A & $-0.00067 \pm 0.0003$ & -0.0016 & 0.0002 & $0.00077 \pm 0.0006$ & -0.0006 & 0.0022 \\
\hline & Group B & $0.00079 \pm 0.0007$ & -0.0008 & 0.0024 & $-0.00057 \pm 0.0004$ & -0.0016 & 0.0005 \\
\hline ANOVA & $\mathrm{P}$ value & \multicolumn{3}{|c|}{$0.091 \mathrm{~ns}$} & \multicolumn{3}{|c|}{$0.0537 \mathrm{~ns}$} \\
\hline
\end{tabular}

CI; Confidence intervals*; significant $(p<0.05) \mathrm{ns}$; non-significant $(\mathrm{p}>0.05)$

Fig.1 prepared tested nanocompsite materials

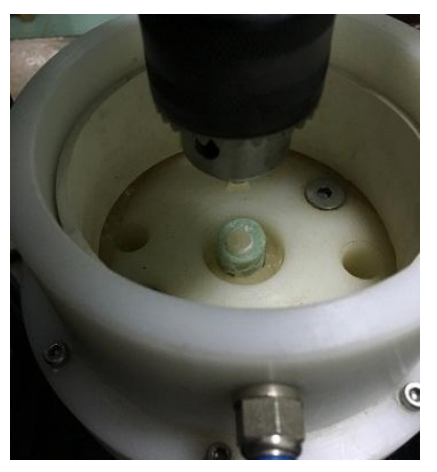

Fig.2 Antagonist enamel samples illustration

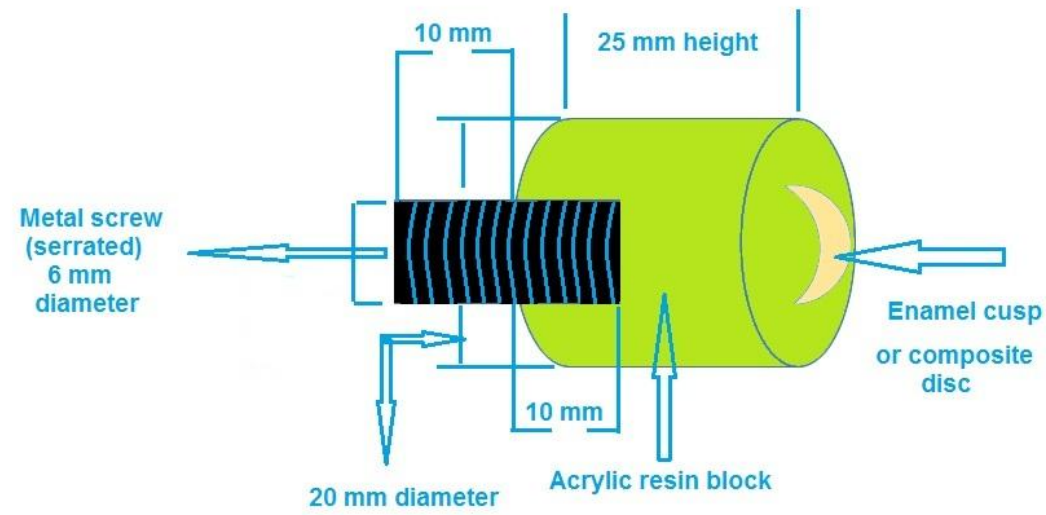


Fig.3 ROBOTA chewing simulator

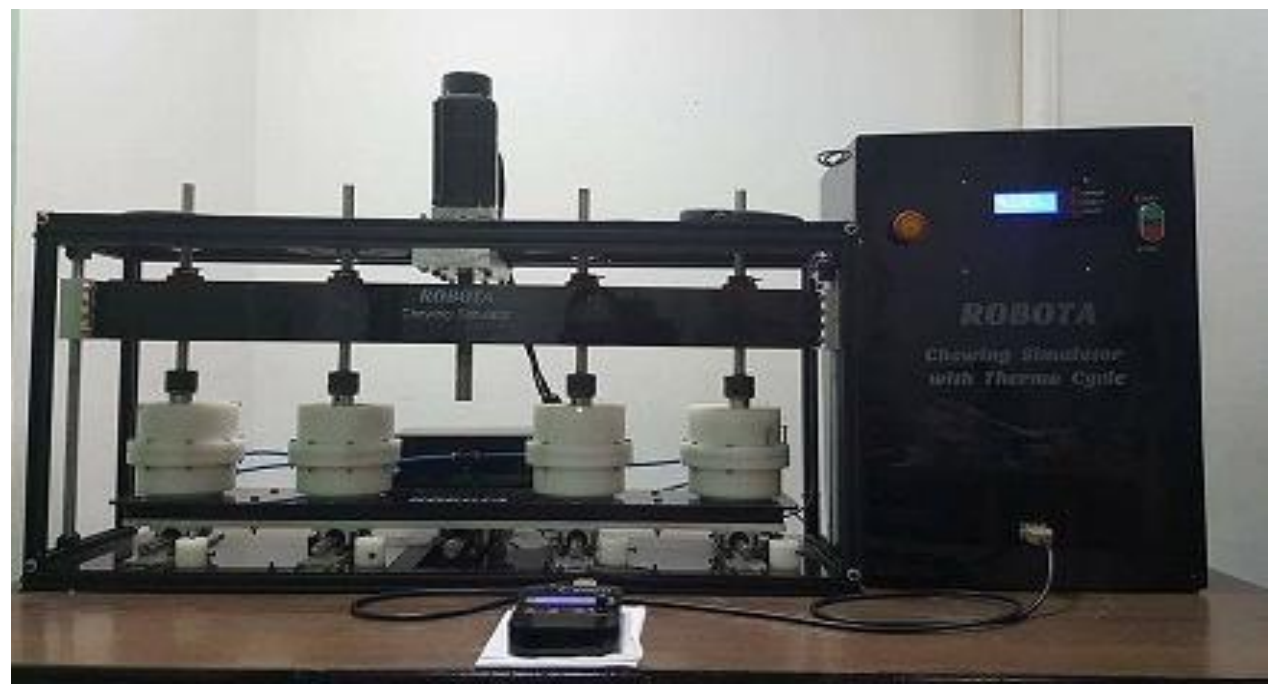

Fig.4 Electronic analytical balance

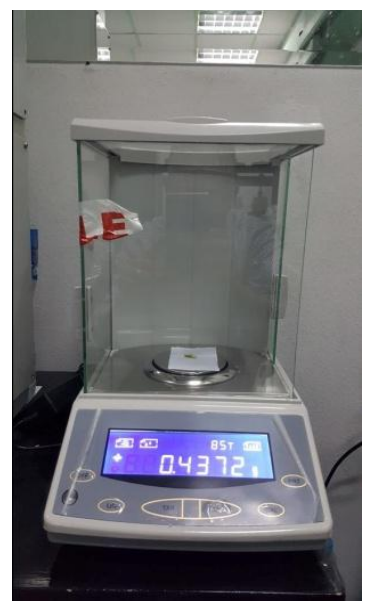

Fig.5 Scope capture digital microscope

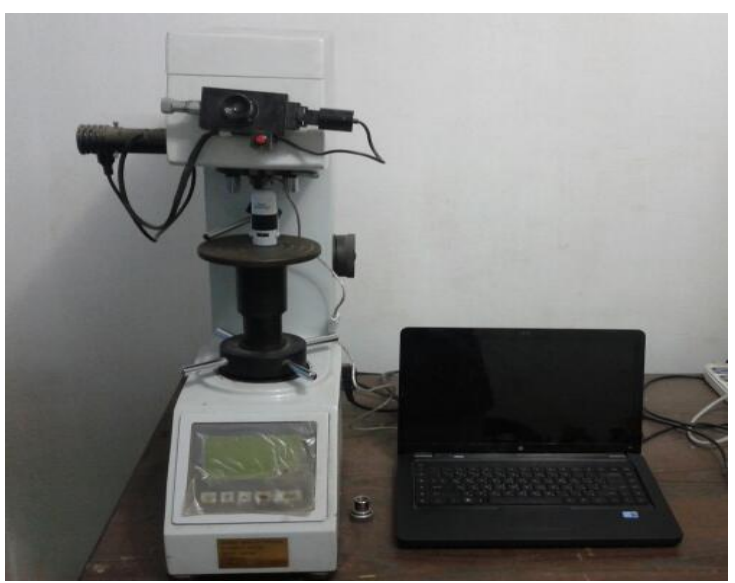


Fig.6 Group A and B reprehensive sample of antagonist cusp surface roughness before wear process. I- Antagonist buccal cusp micrograph II- sample surface plot
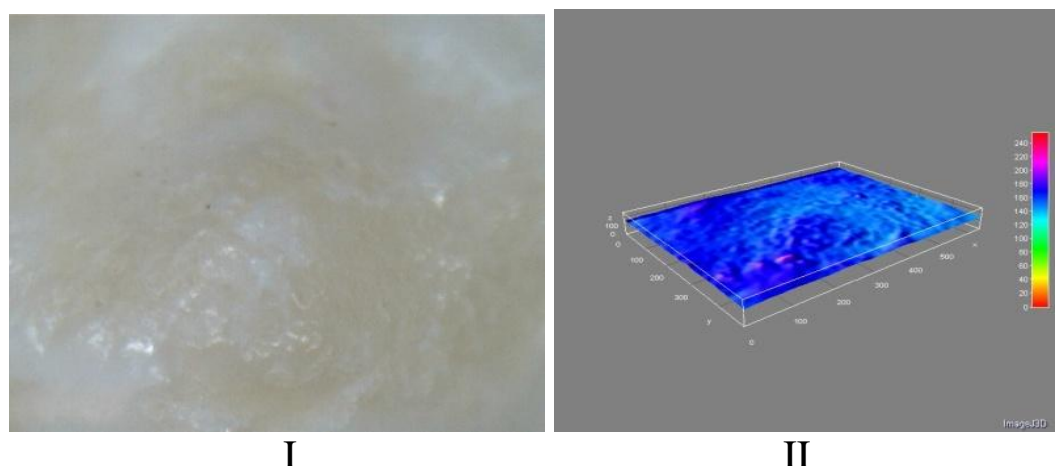

Fig.7 Group A antagonist cusp surface roughness after wear process.

I- Antagonist buccal cusp micrograph II- sample surface plot

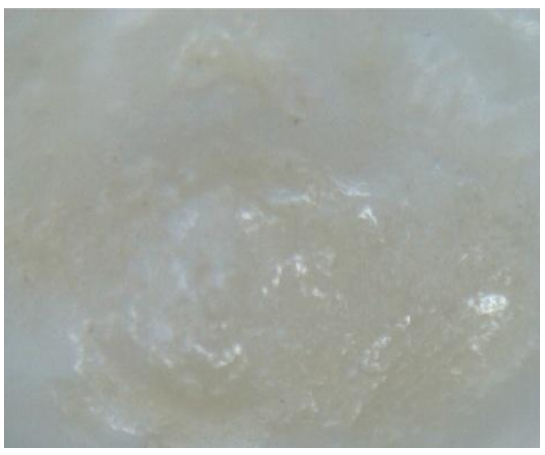

I

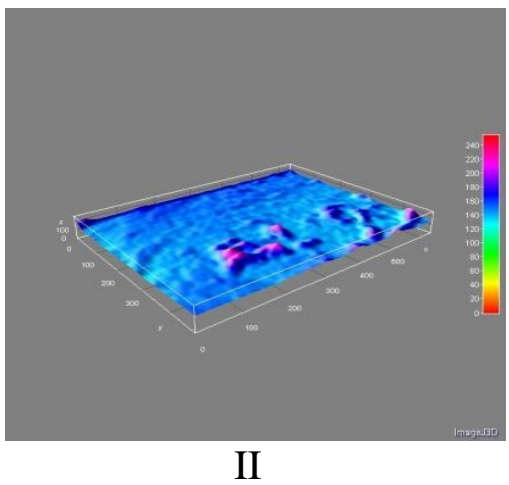

Fig.8 Group B antagonist cusp surface roughness after wear process. I- Antagonist buccal cusp micrograph II- sample surface plot

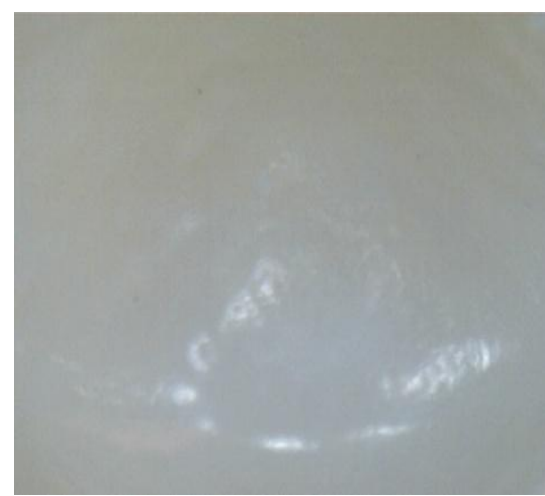

I

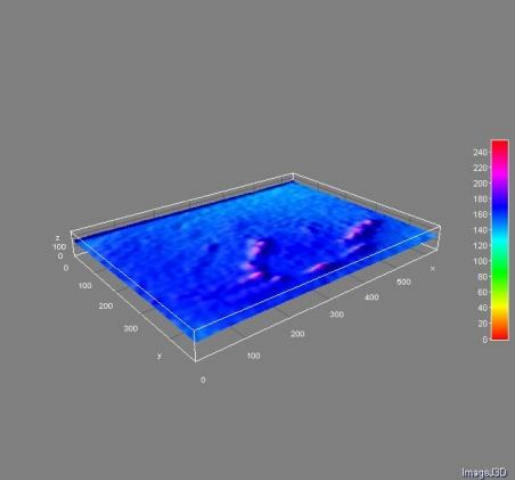

II 
Fig.9 Group A composite samples surface roughness before wear process. I- Composite surface micrograph II- Composite sample surface plot

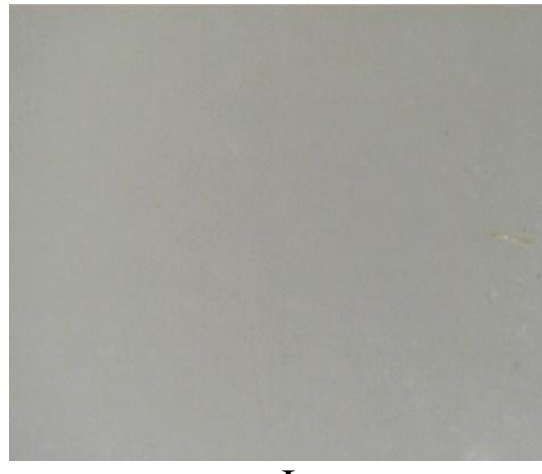

I

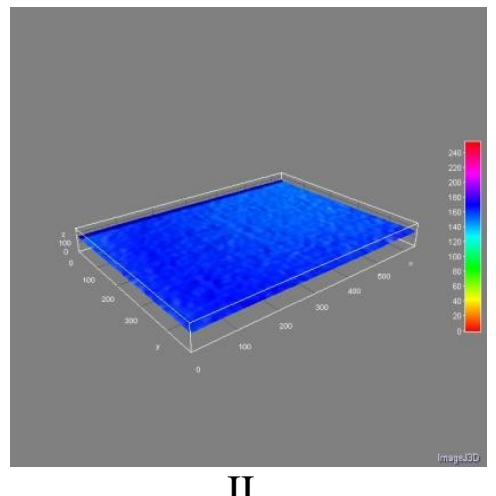

II

Fig.10 Group A composite samples surface roughness after wear process. I- Composite surface micrograph II- Composite sample surface plot

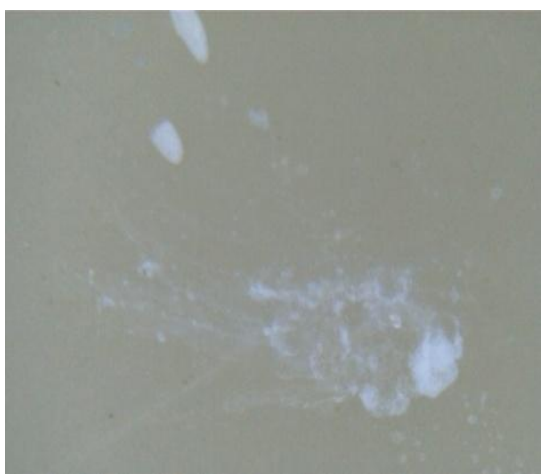

I

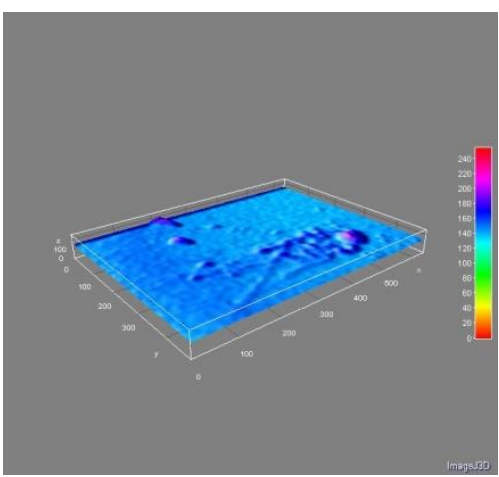

II

Fig.11 Group B composite samples surface roughness before wear process. I- Composite surface micrograph II- Composite sample surface plot

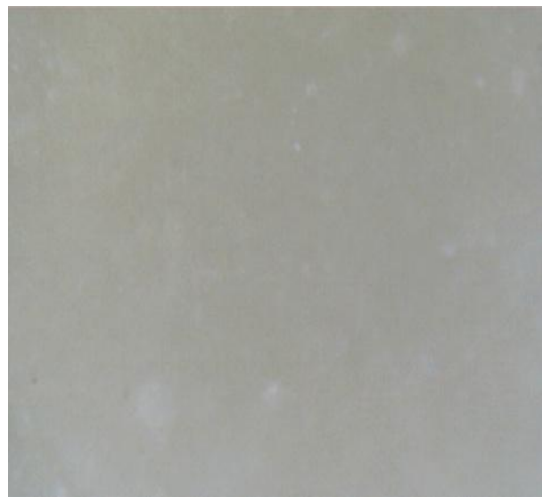

I

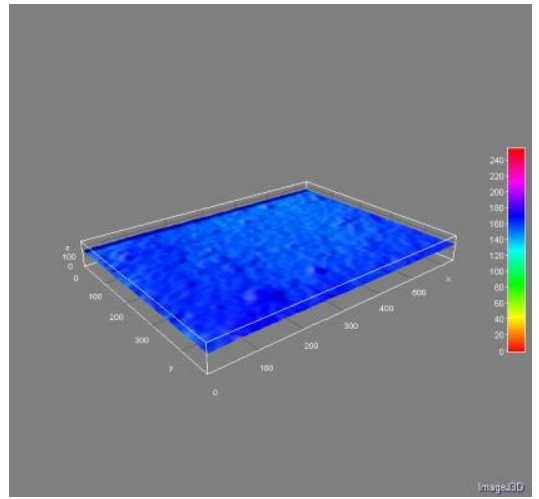

II 
Fig.12 Group B composite samples surface roughness after wear process. I- Composite surface micrograph II- Composite sample surface plot
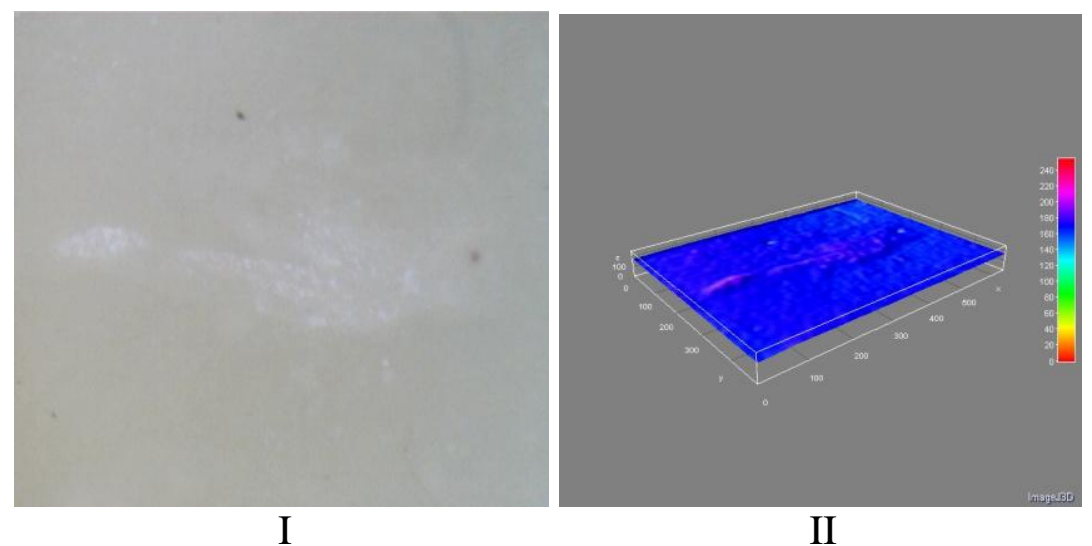

In present study, a two body wear test was conducted to rank the wear resistance of different recent resin composite materials. The pairs of human tooth- Filtek Z350 XT composite samples and human tooth - Bio active restorative materials samples have been subjected to a wear test protocol in this study.

In this study it was found group B composite samples showed non-significant higher surface roughness than group $\mathrm{A}$. and its antagonist cusp showed non-significant higher weight loss than group A antagonist cusp. It was found that group B composite recorded higher was statistically nonsignificant roughness change mean value $(0.00079 \pm 0.0007 \mathrm{Ra})$ than group $\mathrm{A}$ composite mean value $(-0.00067 \pm 0.0003$ $\mathrm{Ra})$. Also it was found that groupA antagonistic cusp showed non-significant higher roughness change mean value than group B antagonistic cusp mean value.

Our findings may be explained as higher enamel weight loss and subsequent wear of tooth antagonist to group B with surface roughness of group B samples caused by glass particles and wear debris that detach during the wear process might behave as an abrasive medium and lead to a 3-body wear mechanism. These findings were coinciding with previous studies that confirmed that these abrasive particles might emphasize the consequences of enamel wear. Although this wear test was run using distilled water, which would help lubricate the contact surface, flush out debris, and reduce heat generation from abrasion, some wear debris may still remain in the wear track and may influence the contact stresses and wear (Fischer et al., 2000; Shimane et al., 2010; Sripetchdanond et al., 2014).

Group A antagonist cusp showed nonsignificant higher roughness change mean value, this may attributed to a harder filler, with high filler load, becomes less abrasive when the particle size is at nano-scale. Nanoparticle Zirconia filler used in group A tested composite inherited it to be less abrasive than glass particles filler, with lower filler load, tested with group B.

These findings matched with several researchers who stated that harder filler becomes less abrasive when the particle size is at nano-scale. The use of hard filler with a large size should be avoided. Though the configuration of the fillers becomes evident on the SEM pictures made after the two and three-body wear tests differences in roughness cannot be found with the profilometer (Ilie et al., 2009; Ruttermann et 
al., 2008).

It was found that group B composite recorded statistically significant higher weight loss mean value $(0.00592 \pm 0.0018$ gr $)$ than group A composite mean value $(0.00027 \pm 0.0004 \mathrm{gr})$. Also It was found that group B antagonistic cusp recorded nonsignificant higher weight loss mean value $(0.01 \pm 0.002 \mathrm{gr})$ than group $\mathrm{A}$ antagonistic cusp mean value $(0.0049 \pm 0.005 \mathrm{gr})$. This weight loss of group B composite samples and antagonist cusp may be due to glass particles leaching out of tested composite samples and these particles act as abrasive medium. The abrasive effect of leached glass partials extends to abrade opposing dentition with subsequent weight loss. As in dental composites wear mechanism, the fillers type plays an important role. Faria et al., (2007) mentioned that during clinical application of composites silica-filled composite has been recommended instead of a glass-filled composite that leaches more filler elements and degrades faster. For tested composite samples group A which show statistically significant lower weight loss than group B, Also group A antagonist showed non statistically significant lower weight loss values than Group B antagonist. These may be explained by the composition of group A tested composite which contain $72.5 \%$ by weight nanoparticles Zirconia filler immersed in rein matrix formed mainly of bis-GMA, UDMA, TEGDMA, PEGDMA and bis-EMA resins. It was found that smaller particles with high filler friction volumes showing high wear resistance. The inter-particle spacing decreasing was the key to improving the wear resistance of composites. Dental Composites interparticle spacing decreasing could be reduced by both decreasing the size and increasing the volume fraction of the fillers (Lim et al., 2009; Manhart et al., 2000).
Within the limitations of this study, the following conclusions can be drawn:

The use of tested bioactive composite was showed a clinically accepted wear resistance with minimal alteration of opposing natural teeth tissue.

Nanoparticles zirconia resin composite tested show high wear resistance with minimal surface topographical changes of natural teeth antagonist.

\section{References}

Attin T, Filli T, Imfeld C, Schmidlin PR 2012. Composite vertical bite reconstructions in eroded dentitions after 5.5 years: a case series. J Oral Rehabil; 39:73-9.

Bartlett D, Sundaram G 2006.An up to 3year randomized clinicalstudy comparing indirect and direct resin composites used to restore worn posterior teeth. Int $\mathbf{J}$ Prosthodont; 19:613-7

Braga SRM, Tachibana TY, Garone-Netto $\mathrm{N}$, et al., 2010. Abrasion resistance of different composites. J Health Sci Inst; 29: 85-88.

Da Rosa Rodolpho PA, Cenci MS, Donassollo TA, LoguercioAD, Demarco FF2006. A clinical evaluation of posterior composite restorations: 17-year findings. J Dent; $34: 427-35$.

DeLong R, Pintado MR, Douglas WH, et al., 2012. Wear of dental composite in an artificial oral environment: A clinical correlation. J Biomed Mater Res Part B; 100B:2297-2306

Faria ACL, Benassi UM, Rodriques RCS, et al., 2007. Analysis of the relationship between the surface hardness and wear resistance of indirect composites used 
as veneer materials.Braz Dent J; 18: 60-64.

Ferracane JL 2013. Resin-based composite performance: are there some things we can't predict. Dent Mater; 29:51-8.

Fischer TE, Zhu Z, Kim H, Shin DS 2000. Genesis and role of wear debris in sliding wear of ceramics. Wear; 245:53-60.

Ghazal M, Albashaireh ZS and Kern M 2008. Wear resistance of nanofilled composite resin and feldspathic ceramic artificial teeth. J Prosthet Dent; 100: 441-448.

Hahnel S, Behr M, Handel G, et al., 2009. Two-body wear of artificial acrylic and composite resin teeth in relation to antagonist material. J Prosthet Dent; 101: 269-278

Hamburger JT, Opdam NJ, Bronkhorst EM, Kreulen CM, Roeters JJ, Huysmans MC2011. Clinical performance of direct composite restorations for treatment of severe tooth wear. J Adhes Dent; 13:585-93.

Hirata M, Koizumi H, Tanoue N, et al., 2011. Influence of laboratory light sources on the wear characteristics of indirect composites. Dent Mater J; 30: 127-135.

Horcas I, Fernandez R, Gomez JM, Colchero J, Gomez-Herrero J, and Baro AM 2007. Review of Scientific Instruments; 78; 013705

Kakaboura A, Fragouli M, Rahiotis C, et al., 2007. Evaluation of surface characteristics of dental composites using profilometry, scanning electron, atomic force microscopy and glossmeter. J Mater Sci Mater Med; 18: 155-63.].

Kurachi C, Tuboy AM, Magalhaes DV, et al., 2001. Hardness: evaluation of a dental composite polymerized with experimental LED-based devices. Dent Mater; 17: 309-315.
Lai, Y.H., Kuo, M.C., Huang, J.C. and Chen, M. (2007). On the PEEK Composites Reinforced by Surfacemodified Nano-silica, Mater. Sci. Eng. A, 458: 158_169.

Lim B-S, Ferracane JL, Condon JR, et al., 2002. Effect of filler fraction and filler surface treatment on wear of microfilled composites. Dent Mater; 18: 1-11.

Ilie N, Hickel R. Investigations on mechanical behaviour ofdental composites. Clin Oral Invest 2009; 13:427-38

Manhart J, Kunzelmann KH, Chen HY, et al., 2000. Mechanical properties and wear behavior of light-cured packable composite resins. Dent Mater; 16: 3340.

Mitra, S.B., Wu, D. and Holmes, B.N. (2003). An Application of Nanotechnology in Advanced Dental Materials, J. Am. Dent. Assoc., 134(10): 1382_1390

Olivera AB, Marques MM 2008. Esthetic restorative materials and opposing enamel wear. Oper Dent; 33(3):332-7.

- Ossama B. Abouelatta2010. 3D Surface Roughness Measurement Using a Light Sectioning Vision System. Proceedings of the World Congress on Engineering Vol I

Pontons-Melo JC, Pizzatto E, Furuse AY, Mondelli J 2012. A conservative approach for restoring anterior guidance: a case report. $\mathrm{J}$ Esthet Restor Dent; 24:171-82.

Ruttermann S, Wandrey C, Raab WHM, Janda R. Novelnano-particles as fillers for an experimental resinbasedrestorative material. Acta Biomater 2008; 4:1846-53.

Shimane T, Endo K, Zheng JH, Yanagi T, Ohno H 2010. Wear of opposing teeth by posterior composite resins- 
evaluation of newly developed wear test methods. DentMater; 29:713-20.

Sripetchdanond J, and Leevailoj C2014: Wear of human enamel opposing monolithic zirconia, glass ceramic, and composite resin: An in vitro study. (J Prosthet Dent; 112:1141-1150

Suwannaroop $\mathrm{P}, \quad$ Chaijareenont $\mathrm{P}$, Koottathape N, et al., 2011. In vitro wear resistance, hardness and elastic modulus of artificial denture teeth. Dent Mater J; 30: 461-468.

Tian, M., Gao, Y., Liu, Y., Liao, Y., Hedin, N.E. and Fong, H. (2008). Fabrication and Evaluation of BisGMA/TEGDMA Dental Resins/Composites Containing Nano Fibrillar Silicate, Dent. Mater. 24(2): 235_243.
Vailati F, Vaglio G, Belser U 2012. Fullmouth minimally invasive adhesive rehabilitation to treat severe dental erosion: a case report. J Adhes Dent; 14:83-92

Wilder Jr AD, May Jr KN, Bayne SC, Taylor DF, Leinfelder KF.Seventeen1999 one year clinical study of ultraviolet-cured posterior composite class I and II restorations. J Esthet Dent; 11:135-42.

Xia, Y., Zhang, F., Xie, H. and Gu, N. (2008). Nanoparticle-reinforced Resinbased Dental Composites, J. Dent., 36(6): 450_455.

Yu-Seok J, Jae-Whang L, Yeon-Jo C et al., 2010. A study on the in-vitro wear of the natural tooth structure by opposing zirconia or dental porcelain $\mathbf{J}$ AdvProsthodont;2:111-5).

\section{How to cite this article:}

Ola M. Sakr. 2017. Evaluation of Bioactive Nano Composite Fillers Effect on Wear Resistance of Composite and Enamel Surfaces. Int.J.Curr.Microbiol.App.Sci. 6(6): 74-86. doi: https://doi.org/10.20546/ijcmas.2017.606.008 